STUDIA UBB PSYCHOL.-PAED., LXVI, 2, 2021, p. 59 - 84

(Recommended Citation)

DOI:10.24193/subbpsyped.2021.2.03

\title{
ONLINE TEACHING. OPPORTUNITIES, CHALLENGES AND RECOMMENDATIONS TO IMPROVE COLLABORATION AND QUALITY OF LEARNING
}

\author{
SERGIU MAXIM1
}

\begin{abstract}
Remote learning, also known as distance education, can be defined as teaching the students with no face-to-face contact with the teacher in class. Once the Coronavirus spread, globally imposed measures became more and more restrictive leading to a major difficulty for the educational systems: identifying fast solutions to the issue of suspending the classes and lectures in-person. The techniques of online and distance learning also needed changes to fulfill the needs of teachers and students, such as presentation, communication, asking questions and formulating answers, practicing the theory through various exercises, testing and feedback. There are several good practices popular now in online education, some of which are described throughout this article. Developing a complete set of skills in students is fundamental for facilitating the educational process and integrating them in the study and/or working groups, but also for preparing them for real life. This article presents some of the most important abilities to take into account by the educational system. However, most recommendations from instructors teaching online are presence-themed. Establishing a strong connection and feeling part of a supportive community is vital for students. Using video or Skype, video announcements instead of text, using the phone are all ways to a faster connection whenever doubts or questions arise. In addition, training and agility are on top of the priorities list: using technologies that help in achieving teaching objectives; teaching online does not mean that materials once used face-to-face are uploaded on an online platform; training is key whereas technology cannot work and there is a need for a back-up plan.
\end{abstract}

Keywords: learning, online, skills, technology, teaching methods, synchronous, asynchronous.

\footnotetext{
${ }^{1}$ Faculty of Political, Administrative and Communication Sciences, Babeș-Bolyai University, Cluj-
} Napoca, Romania, sergiu.maxim@fspac.ro 
ABSTRAKT. Fernunterricht, auch als Fernstudium bekannt, kann als Unterrichten der Schüler ohne persönlichen Kontakt mit dem Lehrer in der Klasse definiert werden. Als sich das Coronavirus ausbreitete, wurden die weltweit verhängten Maßnahmen immer restriktiver, was zu einer großen Schwierigkeit für die Bildungssysteme führte: schnelle Lösungen für das Problem der Auflösung von Unterricht und Vorlesungen vor Ort zu finden. Auch die Techniken des Online- und Fernunterrichts mussten geändert werden, um den Bedürfnissen von Lehrern und Schülern gerecht zu werden, wie zum Beispiel Präsentation, Kommunikation, Fragen stellen und Antworten formulieren, die Theorie durch verschiedene Übungen üben, Testen und Feedback. In der Online-Bildung gibt es mehrere vorbildliche Vorgehensweisen, von denen einige in diesem Artikel beschrieben werden. Die Entwicklung vollständiger Kompetenzen bei den Studierenden ist grundlegend für die Erleichterung des Bildungsprozesses und die Integration in das Studium und/oder die Arbeitsgruppen, aber auch für die Vorbereitung auf das reale Leben. Dieser Artikel stellt einige der wichtigsten Fähigkeiten vor, die im Bildungssystem berücksichtigt werden müssen. Die meisten Empfehlungen von Lehrern, die online unterrichten, beziehen sich jedoch auf die Präsenz. Für die Schüler ist es von entscheidender Bedeutung, eine starke Verbindung aufzubauen und sich als Teil einer unterstützenden Gemeinschaft zu fühlen. Über Video oder Skype, Videoansagen statt Text, das Telefonieren, all diese sind Wege die zu einer schnelleren Verbindung bringen, wenn Zweifel oder Fragen aufkommen. Darüber hinaus stehen Training und Agilität ganz oben auf der Prioritätenliste: Einsatz von Technologien, die dabei helfen, Unterrichtsziele zu erreichen; Online-Lehre bedeutet nicht, dass Materialien, die einmal persönlich verwendet wurden, auf eine Online-Plattform hochgeladen werden; Schulung ist der Schlüssel, während Technologie nicht funktionieren kann und ein Backup-Plan erforderlich ist.

Schlüsselwörter: Lernen, Online, Fähigkeiten, Technologie, Lehrmethoden, synchron, asynchron.

\section{Introduction}

Over time people have been exposed to a variety of learning forms, which were vital for their survival in the world's innovative and evolutionary context. Thus, the learning process is indispensable to adaptation and change no matter its form, nature, length or intensity. 
Beyond the traditional learning methods, more precisely face-to-face teaching, the modernization of virtual technologies and tools has given rise to virtual and remote learning. According to UNICEF in Europe and Central Asia (2020), there are three types of such learning: remote, online and blended.

Remote learning, also known as distance education, can be defined as teaching the students with no face-to-face contact with the teacher in class. This is implemented through correspondence in both written form, such as printed materials and multimedia, such as radio channels, television or online.

Online learning represents the education on the internet, either part of some remote learning programs or as a supplement to traditional teaching methods in class. Students' location can vary from their home to classrooms, as long as safe access to internet is provided, so that they can use the virtual technologies and applications.

Blended learning implies combining the face-to-face teaching methods with the online interaction by using the virtual applications. This can even include remote learning, through the methods previously mentioned.

\section{Digital Trends and Covid-19 Impact on Online Teaching}

From all of the above, remote and online learning, also known as elearning are subjects of topical interest which have developed exponentially in the past few years and continue to increase in popularity to the detriment of classical face-to-face teaching methods. That which was thought to be a temporary short-term solution, only as an individual protection measure against Covid-19 became a habit for educational institutions and the rest of the population directly or indirectly involved in the process. Once the Coronavirus spread, globally imposed measures became more and more restrictive leading to a major difficulty for the educational systems: identifying fast solutions to the issue of suspending the classes and lectures in-person. 
For over a year now, online education has been facing different teaching forms and process improvements regarding the teachers' training, creation and delivery of content and students' learning. Transitioning from the traditional education to the virtual one requires multiple complex choices and the most efficient project management possible so that it allows students to be as active and involved as necessary in their own qualitative development.

Even more, remote and online learning are expected to be an irreversible change, according to multiple surveys and studies conducted between 2020-2021, among which the one coordinated by School Education Gateway (2020), the European online platform for professionals in education between $9^{\text {th }}$ April $-10^{\text {th }}$ May 2020. The results of 4.859 respondents, out of which $86 \%$ being teachers and school directors indicate that more than a half considers that the school practices would not be the same anymore when the schools will reopen and online/remote teaching will continue to grow in volume. More accurately, $44 \%$ of the respondents thought that school will suffer slight changes in the future, with a higher focus on online teaching than before, while $17 \%$ considered that school will be certainly different by integrating more the online teaching methods.

On the same note, CEE Multi-Country News Center (2021) published together with Microsoft an article about the accelerated digital transformation in education as a top priority industry. Considering that during 2020, in-class courses have been suspended for 1.2 billion students globally the concern that arises naturally for all teachers is related to continuing this trend even after the pandemic. Opinions seem to be divided, on the one hand because of the inadequate infrastructure and teachers' training which could deteriorate students' experience, and on the other hand because of the initiatives towards a hybrid educational model that could bring considerable benefits.

Positive examples from European countries such as Croatia, Ukraine, Latvia and Slovenia support the digital transition, the more so as multiple researches prove that online learning can be even more efficient than the traditional one. On average, students recall between $25-60 \%$ more information when done online, compared to $8-10 \%$ from the in-class teaching. Certainly, the 
ONLINE TEACHING. OPPORTUNITIES, CHALLENGES AND RECOMMENDATIONS ...

online teaching efficiency varies depending on group ages, nationality or students' economic and political context which calls for an extra effort from teachers to deliver and sustain an education as much qualitative as possible.

\section{Romanian Context}

When it comes to Romania ${ }^{2}$, the digitalization of the education and training system is being debated since 2016, when the national project “România educată (Educated Romania)" was launched. Since then, a clearer vision together with a series of proposals to be implemented until 2030 was outlined on the following priorities: didactic career, equity of the educational system, professionalization of educational management, qualitative technical education, autonomy, internationalization and qualitative higher education, early childhood education, evaluation of pupils and students.

Although Romania currently has wide-ranging internet connectivity, some steps are still missing in order to ensure all resources and an integrated framework for access to quality education in the digital age. The national strategy regarding the digitalization of the education and training system SMARTEdu launched in public consultation in December 2020 aims to generate a Modern, Accessible School based on digital Resources and Technologies, having as priorities the following: accessibility, connectivity, digital educational ecosystem, innovation, sustainability.

According to this strategy, during 2021-2027 efforts will be made to train and develop teachers' digital skills, improve the infrastructure, stimulate and support the creation of offers and opportunities adapted to the professions of the future, encourage student-centered innovation, create Open Educational Resources (RED), increase partnerships with European and international, both public and private organizations, encourage and promote initiatives on online security, data protection, cyber hygiene, IT ethics. All of these initiatives will be possible through respecting several principles, among which equal access, equity, inclusion, learning personalization, quality, resilience and green economy.

${ }^{2}$ https://www.smart.edu.ro/\#h.xck2kklw9ox5 
The expected result is a flexible, digitized, adaptable, qualitative education system, able to respond to challenges and generate change, together with active citizens, well integrated in the labor market and sustainable economic growth.

\section{Opportunities and Challenges Associated with Online Learning}

It goes without saying that the inevitable, spontaneous transition of education from the physical to the virtual environment was and still is difficult, but even so there are numerous benefits once it is well managed and implemented. One of the advantages and probably the most important also is the flexibility offered to teachers and students. Online learning gives everyone involved the chance to organize their schedule according to the group's agenda, to balance the personal chores and other tasks, to learn at their own pace and strengthen their autonomy and sense of responsibility.

In addition, accessibility is another important aspect, both in terms of the wide collection of courses, trainings and educational programs, as well as the location and personal comfort. On one side, the internet is full of resources adapted to the individual needs concerning knowledge and skills development. Many of the institutions holding online programs also release diplomas and certificates once students complete them. On the other side, students do not need to travel to attend the classes anymore; only an internet connection and a quiet space are enough in order for them to enjoy a complete learning experience. Even during trips and vacations, the learning process can continue through the medium of apps available online (Josep, 2021).

However, just as any other major unexpected change, the digital transformation of education comes with several challenges and barriers. The major issues regarding online learning, which students and educational institutions should have in mind, are related to three categories: learners, instructors, and content development. Learners' issues include their expectations, readiness, identity, and participation in online courses. Instructors' issues comprise transitioning from face-to-face to online, time management and teaching styles. 
Content issues refer to the instructors' role in content development and integration of multimedia and the role of instructional strategies in content development $^{3}$.

The same content previously taught in class, currently assumes a much bigger preparation effort. Furthermore, teachers who have never thought differently than in the traditional way are not at all familiar with the methods needed to change; one more reason why they need training for designing and delivering classes on the internet. They spend much more time for preparing and exploring the online teaching, so they would need a smaller loading (less effective hours to teach) or some financial compensation ${ }^{4}$. Mackey (2016) says that teaching online can require from teachers to relearn individual preferences of each student. The polls, surveys and drawing instruments could help in this sense, not only for the lessons to be more personalized and learner-centered but also for increasing the retention.

Challenges associated with the virtual groups in which differences between individuals emerge are also very important to take into consideration. One research published by Taras, V., Baack, D., Caprar, D., Jiménez, A. \& Froese F. (2021) classifies these differences in two categories: personal and contextual. Personal diversity includes characteristics such as age, gender, language, skills, and values whereas contextual diversity refers to differences in the environments that the team members live in, such as the different levels of economic development and different types of institutions and political systems of their countries. Results demonstrate how the personal diversity can negatively affect team climate, while contextual diversity can positively affect task and group's performance. Numerous studies have shown that less homogeneous teams exhibit more creativity, considering more options and solutions, processing facts more carefully and succeeding in making better decisions.

3 Kebritchi, Lipschuetx, \& Santiague, (2017)

${ }^{4}$ Conrad, lector de la Universitatea Berkeley din California (după O'Malley, S., 2017) 


\section{Role of Teachers and Online Teaching Methods}

Not only is diversity identified between individuals studying together, but also in the content, methods and tools of online teaching which have experienced changes and improvements too along with the modernization of technology and the increasing rate of internet use, especially amongst the younger generation. Information are today at one click away, but so are sources of distraction during a class. This is why it is important for teachers to identify various methods to maintain the attention and active involvement of students for as long as possible, without endangering their well-being or the quality of the information provided.

Boettcher (cf. O'Malley, S., 2017) claims that the mental presence of the teacher is the most important one and this is not about only answering to the questions students address online, but also about the "social presence" in the online class. Even more, they need to encourage their students to be as socially present as possible in their turn too, by sharing experiences, things they have read or seen or even posting photos with them in front of the computer, etc. It is important for the students to have an idea about who their teachers are as humans.

The Community of Inquiry Model, hereinafter referred to as CoI, developed in 1999 by Garrison și Anderson (Garrison, 2017) describes three types of presence: learning, cognitive and social presence. Daspit, Mims, \& Zavattaro, (2015) used the theory of positive psychology when suggesting that the CoI model includes psychological capital (PsyCap) to emphasize the students' positive motivational states. However, Salmons (2020) says that PsyCap is a distinct online presence. Social presence of learning group members is associated with the participation and social interaction level between them, therefore it is considered to be a critical variable in the learning process.

Another perspective on social presence as a theoretical concept is presented by Kenzig (2015) who considers that it can be divided in two different constructs. These are the "social presence", which refers to the degree of 'realness' of the other in the communication and the "social space" meaning the degree to which social interpersonal relationships are salient. The author also 
identifies that social presence in the CoI model is actually integrating both constructs but with an emphasis on social space.

One of CoI model's limitations identified by Majeski, Stover, \& Valais (2018) is the integration and understanding of the emotional presence, solely seen in terms of emotional expression. The authors believe that emotional intelligence would support a much broader role for emotional presence in learning and discuss the relationship between emotional presence and teaching presence and how the latter may foster emotional presence in learners. Students' online motivation is an essential ingredient for academic success. Motivation involves the desire to learn with self-discipline to acquire new information Mickahail (2016).

Not least, the study described by Lohr \& Haley (2018) reveals the fundamental contribution of creating the social presence through the training design. In their research, the authors used an autobiographical memory exercise in an online graduate course and reached to the conclusion that communication and learning improved. Additionally, integrating the social presence encouraged an active and engaged online learning community.

\section{Online Teaching Methods}

The techniques of online and distance learning also needed changes to fulfill the needs of teachers and students, such as presentation, communication, asking questions and formulating answers, practicing the theory through various exercises, testing and feedback. There are several good practices popular now in online education, some of which are described below.

\section{Synchronous Teaching and Learning}

One short definition of synchronous e-learning is the learning on the internet in real time done by an individual or a group of people through direct interaction with the instructor. This can be realized through the available technological infrastructure and tools, usually video and/or audio conferences, live chats or live speeches. 
Participating to synchronous e-learning activities is necessary for students' academic results. Teachers cannot ensure that students who are on the participants list are actually following the online learning tasks. While transitioning from the face-to-face interaction in the traditional classroom to the impersonal virtual room on a screen, lots of teachers need to accept that online classes do not offer the same sense of community as the ones before. Online classes are social classes which are highly based on the ability to communicate efficiently in group. Fisher \& Tucker (2004) affirm that the feeling of belonging, a community with the same interest is one of the key to success when it comes to students that interact exclusively on the internet.

Sobko, Unadkat, Adams, \& Hull (2020) conducted a qualitative study in which they explored the collaborative network learning during a course and they analysed the speech, way of thinking and media used by students during a video conference discussion. By using a socio-cultural context regarding learning and development, the authors concluded that synchronous online engagement and multiple digital technologies have facilitated the construction of students' knowledge and content analysis. They define the collaborative network learning as being built by the dynamic convergence of "actors" working together towards multiple and competing goals.

\section{Asynchronous Teaching and Learning}

Compared to the synchronous learning, the asynchronous one represents learning from the same materials, but in different moments and places, students being independent one from the other in their educational process and also from the instructor's schedule. Materials used in asynchronous learning are usually written materials and/or in video/audio format, previously recorded and distributed to students.

Comer \& Lenaghan (2013) approached the educators' concern regarding the usage of asynchronous online discussions instead of the face-to-face discussions. Starting from the researches on asynchronous online learning and Bloom's taxonomy, the authors introduce the system of "original examples" and "value-added comments" which they developed to promote stimulating, meaningful discussions in which students learn the course material from one 
ONLINE TEACHING. OPPORTUNITIES, CHALLENGES AND RECOMMENDATIONS ...

another. There are described several concrete methods to integrate this system and a guide for instructor facilitation. Their study proves the fact that asynchronous online discussions facilitate students' learning and can even be more inclusive than the ones face-to-face, for some people.

Asynchronous learning is attractive especially to students, because it is their choice as when, where or even if they will participate to specific courses and training programs. This opportunity presents also a risk, associated with the misbelief of many that online learning is easier than in-class learning. The risk of not attending the classes at all or that of navigating a less qualitative educational material can be prevented by a special sort of motivation, with which students would actively assume responsibility over their own educational process through asynchronous online learning platforms.

Glenn, C. W. (2016) examines specific methods to make that possible and to bring more humanity in the online environment in a way that improves retention. Some of the most important in relation to the students require paying higher attention and respectfully approaching their needs and concerns, continuously advising them with regard to their career development, promoting a culture driven by success and encouraging the students to strengthen friendships and connections.

\section{Online Teaching through Collaboration and in Small Groups}

Despite the numerous studies on social interaction within collaborative learning, there is still not enough information about the successful interactions forms in situations of collaborative learning made in front of the screens. After a meta-synthesis of 41 articles about small group work in online courses completed in 2017, Cherney, Fetherston, \& Johnsen argue that there is a lack of consistent definitions within literature about student collaboration online and a lack of interdisciplinary contribution to online course small group literature. In this meta-synthesis, the authors raise awareness regarding the optimal size of an online group, ways of dividing the students in smaller groups, "free-riding" and other concepts. 
Another study on the same subject was completed in 2016 and indicates that interaction in collaborative situations is usually more related to the group, rather than the learning task. After this qualitative case study made during a university course, Vuopala, Hyvönen, \& Järvelä concluded two relevant aspects: group-related interaction has a higher frequency and is concentrated mostly on coordination of group work, such as planning and organizing group activities, whilst task-related interaction occurs more rarely and in a more rigid way, mostly in the form of comments or answers to earlier messages.

\section{Gamification}

The concept of gamification can be defined as an approach using gaming elements in contexts with no entertaining or playful nature, in order to involve people in their activities. Regarding education, including gamification methods can bring many benefits, especially maintaining the attention and active participation of students, according to authors Çakiroğlu, \& Kiliç (2018).

After creating two different gamification scenarios the authors applied them within a study and its conclusions are that it is preferred for teachers to include such methods in materials design, given how students can spend hours in the virtual environment and this kind of activities can offer them satisfaction and entertainment. Games that are already online can be a suitable activity either for relaxation and detachment from everyday life or learning and practicing critical thinking, decision making abilities and discernment. In addition, the possibility for students to win points after successfully completing each game level can be thrilling and it stimulates the competition in a group, but it can also contribute to an increased focus on task and interaction with teachers.

\section{Possible Objectives of Education}

Generally, operating based on objectives implies managing processes by following a concrete action plan with the aim of attaining the desired results, everything being well calculated, monitored and periodically evaluated in order to validate the progress and further steps. For educational institutions and industry 
experts, such examples of objectives could be teaching and learning specific cognitive, non-cognitive and mixt abilities, delivering materials of high-quality, attractive, easy to process by students, creating a safe learning environment, promoting inclusion and equity.

Besides theoretical and practical knowledge about diverse professional domains and personal areas, students' education nowadays should focus to the same extent on developing specific social and collaborative skills. Many courses created for getting students ready for real life started to include competencies specific to emotional intelligence, such as self-control and discipline, conflict management, cultural awareness and inspirational leaderships.

Along with the digital transition, the educational objectives can be debated from the perspective of teachers as beneficiaries. More precisely, one relevant objective could be the improvement of digital skills through training and specific programs for teachers. Replacing the face-to-face interaction and traditional teaching forms is an objective itself, which needs a certain level of selfeducation and adaptation to the new trends. The best advice for teachers is to take a step back and concentrate on what matters most. Prioritizing an open, clear communication channel with both students and parents is a first essential step towards achieving the proposed goals.

\section{Learning Cognitive and Non-cognitive Abilities}

As mentioned above, developing a complete set of skills in students is fundamental for facilitating the educational process and integrating them in the study and/or working groups, but also for preparing them for real life. This article presents below some of the most important abilities to take into account by the educational system.

\section{Critical Thinking}

Redmond (2014) affirms that critical thinking and in-depth knowledge can occur through reflective processes. Whenever students go through the four stages of cognitive presence (triggering, exploration, integration, resolution) the processes of discussion and reflection are important in developing deep 
understanding. When instructors structure online discussions appropriately, students are able to share and document their own thinking and reflect on their contributions and the perspectives of others while developing new or deeper knowledge.

\section{Self-Directed Learning}

One of the specialized books on the self-directed learning theme is "Assessment Strategies for Self-Directed Learning", written by Costa \& Kallick (2004). While elaborating the necessary conditions for self-learning, the authors mention that instead of requiring compliance, a new role needs to be taken in mediating and supporting others, in order to become more selfconfident, more self-responsible and able to refer to their own self. It is easier, according to the authors, to teach others to be self-directed as long as the organization supports this kind of efforts. In the fifth chapter of the book, they show the way in which teachers mediate the learning of these abilities through designing lessons, units and training activities, creating the conditions for self-directed learning, generating and intensifying reflective dialogue and serving as a model for learners.

\section{Time Management}

Time management and efficiency of solving practical tasks are a challenge for both students and teachers, especially in the online environment, where fun is just a click away and the pitfall of procrastination can be difficult to avoid. Even more, as communication is not necessarily in real time anymore, the spontaneous texts, phone calls or video calls are very common and this can generate a certain curiosity and an impulse to always stay connected.

When it comes to a reasonable time management, O'Malley (2017) states that teachers should not be available $24 / 7$, neither engage themselves in 1-1 interactions with 30 students. Plus, the teacher should not respond to each and every posting written by students. When teachers do so, students start to contact them in private, when the online discussion should actually be held in between classmates. 
ONLINE TEACHING. OPPORTUNITIES, CHALLENGES AND RECOMMENDATIONS ...

\section{Equity and Inclusion}

The concept of equity must be approached from a multidimensional perspective and adapted to two main needs of a modern society: political-institutional, through the principle of justice and theoretical-academic, by ensuring the highest possible quality of inclusion in education. By integrating the concept of equality, equity is made up of three essential pillars: equal opportunities, treatment and results. Transposed into the educational system, equity means taking into account the socio-economic, political and cultural environment of the learners and ensuring correct compensation strategies, so as to avoid any opportunity for discrimination. In this regard, Castelli, Ragazzi și Crescentini (2012) suggest the following methods to ensure equity in teaching and learning contexts:

1. Regulating the exercise of rights more strictly, particularly the right to education

2. Frequent communication and strengthened relations with the community, especially with the learners' families, for a better mutual understanding and an increased social integration

3. Development of specific expertise in terms of discrimination and integration among teachers

Morgan, Giggins, Miller, Pierce, Boone \& Tandy (2016) studied different types of online teaching of social abilities and found out that these are efficient in identifying the behavioral issues in the online environment. Using technology creates new natural environments for social participation and new rules of interaction. Some theories suggested that students with emotional or behavioral disorders would have social difficulties in online settings. It is critical to understand the elements of diversity and the way these impact the interaction in online, but also the overall final performance of the group and individuals.

Another important aspect in choosing the technologies and online teaching methods is the accessibility for students with disabilities. Ross (2019) evaluates the attitudes and perceptions of the learning management systems (LMS) in creating an attractive learning experience and, in the same article, he evaluates the possibility of using Slack, a communication business tool as an 
additional LMS tool. The author reaches the conclusion that Slacks helps to improve students' perceptions on the online class as a real-life experience, as well as the learning results perceived from the group work.

\section{Online Teaching Efficiency}

Regardless of the pursued objective, one critical indicator is the efficiency of the processes and work done by each person in particular. As for online teaching, its efficiency depends on the technologies used, content types and design, teaching forms and styles approached by the instructors and also on communication styles, frequency and methods. Students' age is not to be neglected as a defining factor, because the younger they are, the bigger their orientation towards digital working methods will be. Even the adults used to traditional methods currently appreciate more the online tools.

\section{Multimedia Tools}

Creativity, flexibility and the usage of a wide range of collaboration and involvement tools are absolutely essential for a well-trained teacher who could promote inclusion, personalization and intelligence. For example, in Romania the digital transition has had a positive impact regarding the collaboration between teachers and instructors, thus creating lots of virtual spaces with access to open educational resources (RED). The digitaledu ${ }^{5}$ platform is one such example as the core of an initiative to support significant learning activities adequate for the $21^{\text {st }}$ century.

People can find here over 4.500 suggestions of learning activities and free resources, reviewed and validated by industry experts dedicated to this project. Teachers can filter their search according to factors such as curricular area, field of study, education level or activity type while materials are available in written format, video, audio, images, evaluation files or even games, applications and simulations. These kinds of platforms are suitable for both teachers and learners, being very useful and in ongoing development.

${ }^{5}$ https://digitaledu.ro/ 
ONLINE TEACHING. OPPORTUNITIES, CHALLENGES AND RECOMMENDATIONS ...

\section{Multimedia Teaching Materials}

Boettcher \& Conrad (2010) allege that teaching or lecturing parts need to be removed. There is a higher need for a mix of discussions, collaborative learning activities, video and audio files, written exercises and casual short video presentations. Vai, an e-learning consultant and former president of English Language department at New School in New York - after O'Malley (2017) claims that the student should be engaged, therefore pages of text or an hour-long video have to be eliminated. Presenting the information should be done in 10-minute "chunks" with ample white spaces and incorporating photographs which illustrate the written text. It is also recommended that the titles to be colored.

Adding to this perspective, Kizilcec, Bailenson \& Gomez (2015) believe that it is preferred for the lectures to be recorded ${ }^{6}$ rather than streamed live. In case some students have technical difficulties or struggle with internet access, they can watch the recording some other time. Lectures where teachers show their faces are more efficient than slideshows. Slides should be interspersed with videos of the teachers. Videos should be short, as the ones longer than 15 minutes can be difficult to download and also distract the learner. For longer lessons, teachers are recommended to record two or three separate videos. Before shooting the lectures, it is suggested to test the slides on a smartphone in order to make sure that text is readable on a small screen also. Not least, double-checking the font sizes, colors and template design would be useful.

One study made in Russia ${ }^{7}$ about learning English as a foreign language proves how children understand the material much better if the teaching method covers as much as possible the five human senses including interaction with others, while adults benefit more from their abstract thinking and appealing to their own life experiences and expectations. In plus, the same study recommends setting up a different resolution time for tasks, in order to retain students' attention depending on their age: while a 2 years old child cannot focus

${ }^{6}$ https://theconversation.com/coronavirus-14-simple-tips-for-better-online-teaching-133573

${ }^{7}$ Arkhipova et al. (2018) 
more than five minutes on the same thing, a teenager manages to do this for up to 20 minutes, after which he or she will get bored. Adults, on the other hand have a longer concentration span being more self-disciplined.

Nonetheless, expecting from a teacher to design video and written materials for a whole semester is not realistic, which is why it would be advised to use some of the resources already available. There are many one click away online materials for students and learners. Naturally, teachers need to ensure that these are accessible otherwise they could receive plenty of spam emails from the ones trying but failing to retrieve them. Instructions should be clear, given that watching a 15 minutes video can be irritating for some. One solution for this is to tell them directly the exact minute to start watching.

When providing more than two resources it is better to label them in a simple way according to their difficulty or importance. Moodle, Edmodo și Blackboard include many functions to create interactive learning activities such as quizzes. Expectations should also be reasonable. Whenever quizzes are created, questions and answers should be linked to clear references from the learning materials.

Kidd, W. (2012) studied the usefulness of podcasts as an educational tool. The author places the adoption of podcasts for teaching and learning in the context of a short history of e-learning and makes a brief review on the suggestion that e-learning and social media fit the framework of a new learner type the digital native. According to this article, podcasts are a simple, cheap, approachable and strong way to explore learning opportunities through social media.

Additional possible reasons endorse the integration of social media in teaching such as: (1) expose learners to practices, (2) extend the range of educational environment, and (3) promote collaborative learning through social interaction. Complementing this idea, Gruzd, Haythornthwaite, Paulin, Gilbert, \& del Valle identified in their study in 2018 six distinct elements that support using social media in teaching: (1) facilitation of learners' involvement, (2) teaching organization, (3) employment of external resources, (4) improving learners' concentration on the content, (5) forming practice communities, and (6) discovering resources. 
ONLINE TEACHING. OPPORTUNITIES, CHALLENGES AND RECOMMENDATIONS ...

\section{Multimedia Homework}

The technologies' advancement requires from the users an agile approach, which facilitates the increase of youth's digital ability. Learners often outperform teachers in their knowledge of using the internet, an additional reason why they should be allowed to use digital tools to do their homework. Although it is faster for a teacher to evaluate written exams, it might be easier for students to do a PowerPoint or video presentation because they can express themselves better in this way (King, after O'Malley, S., 2017).

In the event of written homework like doing a summary of the lectures, teachers should mention that no serious report is required. Making this a mandatory assignment but without high stakes, chances are that students will achieve better results. A set of 15 quiz questions or a 300-word limit text should be enough to keep students engaged for about 30 minutes. Teachers cannot verify if everyone participates in class, hence it is better to use options like automating checking and grading features from the learning management system in place.

\section{Virtual Communication}

Online groups are useful for students to discuss between themselves, help one another, etc. Teachers can post some questions as an ice-breaker to start the conversation. This thing will enable learners to take control. Sharing emotions can be helpful online too, so teachers are encouraged to tell students if it is the first time for them teaching online, ask them help in need and tell them they are doing the best they can. Whenever things seem to work out, they should be repeated because even in online, students do not like frequent changes in their learning style.

Same study from Arkhipova et. al (2018) mentioned above introduces the attitude towards making mistakes, something easily observable in communication and sociability. If children are generally sociable and do not worry too much about making a mistake, for adults things are different. Adults care if their mistakes are corrected publicly, which could make them feel anxious and avoid further public speaking opportunities. Situations when students fear making a 
mistake could appear when teachers are extremely demanding which will complicate the educational process, thus it is better for teachers to avoid this kind of attitude.

Pifarré, Guijosa, \& Argelagós (2014) declare that it is important for teachers to know how blogs work. They have studied the way blogs can be used to support collaborative interaction between students and how exactly can this process promote the creation of CoI to develop critical thinking and significant learning. Some of the things teachers should take into consideration when blogs are incorporated in teaching and learning are described in the authors' article.

Another means of communication very popular and massively applied within the population, both in education or economic environment and personal life is the email. Email conversations grant information storage and instant replies, sending documents and other multimedia materials. Dehghani, Shakery, Asadpour \& Koushkestani (2013) have explored in their study two new learning approaches with multiple functions, LExLinC și LExTreC, in order to reconstruct linear structure and tree structure of conversation threads in email data. These proposed methods have proven to be highly effective in detecting conversation threads and also adaptable to new environments by automatically adjusting the features and their weights.

\section{Feedback and Learning Results Evaluation}

Constructive feedback and fair evaluation are utterly important but when students' progress and results are being evaluated based on written papers and projects evaluation, there is still a need to more debate over ways of keeping them engaged and helping them evolve.

The premise from which Cartner \& Hallas (2020) started in their research is that there is a gap between the technology used for teaching and learning and that used in assessment. Digital technologies such as blogs, Facebook, Twitter, podcasts and newsletters are being increasingly incorporated in the educational process. On the other hand, evaluation is usually done only through traditional essay and frequently in written format. The authors suggest that an alignment between digital technologies and results of course design, activities and evaluations is necessary as a first step. 
ONLINE TEACHING. OPPORTUNITIES, CHALLENGES AND RECOMMENDATIONS ...

One valuable idea would be to establish a virtual time slot after hours to invite students to discuss any difficulties and questions they may have, but also to request feedback. The meeting should be optional and relaxing, it is mostly important for students to know they have this possibility to connect.

\section{Recommendations for Online and Remote Learning}

In conclusion, this article proposes some tips and recommendations as part of a relevant selection from all of the existing. Some general guidance for online teaching that supports everything analyzed above is proposed by Dunlap \& Lowenthal in an article published in 2017. In order to encourage learners' success, feedback must be relevant, specific, individual and also group-related; grading must be constant, weekly if possible; online activity has to be interactive and funny, students should be allowed to create and post materials, look for resources, answer through video, use applications like screencasting, Pinterest, etc; it is good for students to have the freedom to choose activities they want; the ones that seem to be afraid must be involved; assigning roles through weekly turns and using a discussion protocol is highly recommended, as well as collaborative working projects by using Google Docs as an example of available tools.

In terms of interaction, public presentations and teamwork it is noted that in the traditional classroom, some students would never participate to discussions or ask questions. Usually, this is caused by either being shy or not being engaged. Online, participation is mandatory but it can be as intimidating as in the face-to-face class if students are required to speak in front of many colleagues. King (quoted by O'Malley, 2017), the academic director of the master's program in emerging media from Loyola University Maryland's recommends dividing the online classes of 20-30 students in no more than 10 people for discussions, collaboration and group activities. King says that being maximum 10 people makes it easier for them to coordinate their time and the barriers will diminish even if each one has to participate.

Probably the best to give advices about teaching online are the teachers themselves, which is why four recommendations are detailed below quoted directly from one of them, Kareem Farah (2020): 
1. Simplicity, especially since online, students cannot rely on the fact that other pupils will help them in case they did not understand something, as it was in the traditional classroom. Misunderstandings can be prevented by simple and clear instructions. Access to PDF documents can help students find answers when in doubt. However, this approach requires more preparation from the teacher, ordering ideas, flexibility and conciseness in the delivery of information.

2. A digital home base. It can be the one provided by the educational institution, an LMS platform - Learning Management System such as Canvas or Google Classroom or it can even be an original self-created class website. The author suggests Google Sites thanks to its simplicity and ease of use. No matter how many online spaces are being used, it is good for students to know the home base platform where they can find all necessary information and news. Familiarity is the key, and students should be able to feel comfortable and go to the same place to access the same tools. As remote learning amplifies the challenge of learners' attendance in class and they need to take control of their own learning process, the teachers' goal should be the one of creating a clear framework that allows them to do that.

3. Prioritizing longer, student-driven assignments. When teaching moves to online, teachers cannot correct mistakes on the fly or suddenly pivot when kids are disengaged. For a better time efficacy and sanity, teachers need to plan projects and homework on the long term which allows students to get off the computer and teachers to plan the next learning units. The focus should be on students' autonomy and clarity about learning objectives and deadlines. When possible, it is suggested to create opportunities for students to discuss what they learn with their families and even include an element of students' choice to build engagement.

4. Individual touch-points. Human connection cultivated in traditional class is what students will miss the most. Unfortunately, little interactions in the hallways before or after class, during breaks cannot be replaced. As tempting as it may be for teachers to focus mainly on the content, what matters most is to create ways in which students could manifest their individuality. Emails, video messages, phone calls or comments on shared documents 
can be great ways of doing this. One steady structure needs to be created and respected by everyone involved. Undoubtedly, students will appreciate this and perceive this as an investment from teachers, no matter how difficult to do it may seem. Teachers have to be indeed patient and invest some extra time so that, little by little, the engaging distance learning experience becomes fully cultivated.

However, most recommendations from instructors teaching online are presence-themed. Establishing a strong connection and feeling part of a supportive community is vital for students. Using video or Skype, video announcements instead of text, using the phone are all ways to a faster connection whenever doubts or questions arise. In addition, training and agility are on top of the priorities list: using technologies that help in achieving teaching objectives; teaching online does not mean that materials once used face-to-face are uploaded on an online platform; training is key whereas technology cannot work and there is a need for a back-up plan.

Knowing how technologies change and evolve, we must all remain open and try new things. Moreover, even the action plan for digital education for the period of 2021-2027, published by the European Union (2021) contains a broad vision of the European Commission for a "for a high quality, inclusive and accessible digital education in Europe". With two strategic priorities, the plan provides steps for the development of the digital education ecosystem by improving infrastructure, teachers and instructors, content and tools but also the development of digital skills and competencies from an early age.

\section{REFERENCES}

Arkhipova, M. V., Belova, E. E., Gavrikova, Y. A., Lyulyaeva, N. A. \& Shapiro, E. D. (2018). Blended Learning in Teaching EFL to Different Age Groups. Springer International Publishing AG. DOI https://doi.org/10.1007/978-3-319-75383-6_49.

Baisley-Nodine, E., Ritzhaupt, A. D., \& Antonenko, P. D. (2018). Exploring social presence within an online course using Twitter. E-Learning and Digital Media, 15(5), 235-253. 
Biroul Regional UNICEF pentru Europa şi Asia Centrală (2020). Crearea unor sisteme de educaţie reziliente în contextul pandemiei de COVID-19: Considerente pentru factorii de decizie de la nivel naţional, local şi de unitate şcolară. https://www.unicef.org/romania/media/2836/file/Crearea\%20unor\%20 sisteme\%20de\%20educa\%C5\%A3ie\%20reziliente \%20\%C3\%AEn\%20contextul\%20pandemiei\%20de\%20COVID-19.pdf

Boettcher, J. V. \& Conrad R.-M. (2010). The Online Teaching Survival Guide: Simple and Practical. Hoboken: John Wiley \& Sons.

Cartner, H., \& Hallas, J. (2020). Aligning assessment, technology, and multi-literacies. ELearning and Digital Media, 17(2), 131-147.

Castelli, L., Ragazzi, S. \& Crescentini, A. (2012). Equity in education: a general overview. Procedia - Social and Behavioral Sciences 69 ( 2012 ) 2243 - 2250.

Çakiroğlu, Ü., \& Kiliç, S. (2018). "How to gamify?: Example scenarios for participation in synchronous online learning." E-Learning and Digital Media, 15(5), 254-266.

CEE Multi-Country News Center (2021). The irreversible change of education - for good. https://news.microsoft.com/en-cee/2021/02/23/the-irreversible-changeof-education-for-good/

Cherney, M.R., Fetherston, M., \& Johnsen, L.J. (2017). “Online Course Student Collaboration Literature: A Review and Critique" in Small Group Research

Comer, D. R., \& Lenaghan, J. A. (2013). "Enhancing Discussions in the Asynchronous Online Classroom: The Lack of Face-to-Face Interaction Does Not Lessen the Lesson." Journal of Management Education, 37(2), 261-294.

Costa, A. L. \& Kallick, B. (2004). The teacher's role in self-directed learning. In Experts in Assessment ${ }^{\mathrm{TM}}$ : Assessment strategies for self-directed learning (pp. 98-115). Thousand Oaks, CA: Corwin Press https://doi.org/10.4135/9781483328782.n5

Daspit, J. J., Mims, T. C., \& Zavattaro, S. M. (2015). “The Role of Positive Psychological States in Online Learning: Integrating Psychological Capital Into the Community of Inquiry Framework." Journal of Management Education, 39(5), 626-649.

Dehghani, M., Shakery, A., Asadpour, M., \& Koushkestani, A. (2013). A learning approach for email conversation thread reconstruction. Journal of Information Science, 39(6), 846-863.

Digitaledu - Situații de învățare cu instrumente digitale și resurse educaționale deschise (2019). https://digitaledu.ro/

Dunlap, J.C. \& Lowenthal, P.R. (2017). Online educators' recommendations for teaching online: Crowdsourcing in action.

DOI: https://doi.org/10.5944/openpraxis.10.1.721 
ONLINE TEACHING. OPPORTUNITIES, CHALLENGES AND RECOMMENDATIONS ...

European Union (2021). Digital Education Action Plan 2021-2027. https://ec.europa.eu/ education/education-in-the-eu/digital-education-action-plan_ro

Farah, K. (2020). 4 Tips for Teachers Shifting to Teaching Online https://www.edutopia.org/article/4-tips-supporting-learning-home

Fisher, M., \& Tucker, D. (2004). "Games Online: Social Icebreakers That Orient Students to Synchronous Protocol and Team Formation." Journal of Educational Technology Systems, 32(4), 419-428.

Garrison, D. R. (2017). E-learning in the 21st century: A community of inquiry framework for research and practice ( $3 \mathrm{rd}$ ed.): Routledge.

Glenn, C.W. (2016). "Adding the Human Touch to Asynchronous Online Learning" in Journal of College Student Retention: Research, Theory \& Practice, 19(4), 381393.

Josep, G. (2021) 5 Reasons Why Online Learning is the Future of Education. https://www.educations.com/articles-and-advice/5-reasons-online-learningis-future-of-education-17146

Gruzd, A., Haythornthwaite, C., Paulin, D., Gilbert, S., \& del Valle, M. E. (2018). Uses and Gratifications factors for social media use in teaching: Instructors' perspectives. New Media \& Society, 20(2), 475-494.

Kebritchi, M., Lipschuetx, A. \& Santiague, L. (2017). "Issues and Challenges for Teaching Successful Online Courses in Higher Education: A Literature Review "Journal of Educational Technology Systems.

Kidd, W. (2012). Utilising podcasts for learning and teaching: a review and ways forward for e-Learning cultures. Management in Education, 26(2), 52-57.

Kizilcec, R. F., Bailenson, J. N., \& Gomez, C. J. (2015). The instructor's face in video instruction: Evidence from two large-scale field studies. Journal of Educational Psychology, 107(3), 724-39. https://doi.org/10.1037/edu0000013

Lohr, K. D., \& Haley, K. J. (2018). "Using Biographical Prompts to Build Community in an Online Graduate Course: An Adult Learning Perspective.” Adult Learning, 29(1), 11-19.

Mackey, T. (2016). “Learner-Centered Techniques," în The SAGE Encyclopedia of Online Education de Steven L. Danver

Morgan, J.J., Giggins, K., Miller, S., Pierce, T.B., Boone, R. \& Tandy, R. (2016). “Teaching Online Social Skills to Students with Emotional and Behavioral Disorders,". Journal of Special Education Technology.

Majeski, R. A., Stover, M., \& Valais, T. (2018). "The Community of Inquiry and Emotional Presence." Adult Learning, 29(2), 53-61. 
Mickahail, B. (2016). "Student motivation." In S. Danver (Ed.), The SAGE encyclopedia of online education (pp. 1045-1048). SAGE Publications, Inc. https://doi.org/10.4135/9781483318332.n337

Ministerul Educației și Cercetării (2020). Strategia privind digitalizarea educației din România. https://www.smart.edu.ro/\#h.xck2kklw9ox5

Morgan, J.J., Giggins, K., Miller, S., Pierce, T.B., Boone, R. \& Tandy, R. (2016). “Teaching Online Social Skills to Students with Emotional and Behavioral Disorders,". Journal of Special Education Technology.

O'Malley, S. (2017). 7 guidelines for effective teaching online. Inside Higher Ed. https://www.insidehighered.com.

Pifarré, M., Guijosa, A., \& Argelagós, E. (2014). Using a Blog to Create and Support a Community of Inquiry in Secondary Education. E-Learning and Digital Media, 11(1), 72-87. https://doi.org/10.2304/elea.2014.11.1.72

Redmond, P. (2014). Reflection as an Indicator of Cognitive Presence. E-Learning and Digital Media, 11(1), 46-58.

Ross, S.M. (2019). "Slack It to Me: Complementing LMS With Student-Centric Communications for the Millennial/Post-Millennial Student". Journal of Marketing Education.

Salmons, J. (2020). Making A Sudden Transition To Teaching Online: Suggestions And Resources. https://www.socialsciencespace.com/2020/03/making-a-suddentransition-to-teaching-online-suggestions-and-resources/

School Education Getaway (2020). Sondaj privind învățarea online și la distanță - Rezultate. https://www.schooleducationgateway.eu/ro/pub/viewpoints/surveys/ survey-on-online-teaching.htm

Sobko, S., Unadkat, D., Adams, J., \& Hull, G. (2020). "Learning through collaboration: A networked approach to online pedagogy." E-Learning and Digital Media, 17(1), 36-55.

Stuntz, J.A. (2016). "Student Participation” în The SAGE Encyclopedia of Online Education de Steven L. Danver

Taras, V., Baack, D., Caprar, D., Jiménez, A., Froese F. (2021) Research: How Cultural Differences Can Impact Global Teams https://hbr-org.cdn.ampproject.org/c/s/hbr.org/amp/2021/06/researchhow-cultural-differences-can-impact-global-teams

Vuopala, E., Hyvönen, P., \& Järvelä, S. (2016). Interaction forms in successful collaborative learning in virtual learning environments. Active Learning in Higher Education, 17(1), 25-38. 